\title{
Ameliorative Effect of Exercise Training on Age-Related Vascular and Biochemical Changes in Rats
}

\author{
MOHAMED H. HASSAN, M.D.; OMNIA AMEEN, M.D.; EMAN I. EL-GIZAWY, M.D. and \\ SAMAR RASHAD, M.Sc. \\ The Department of Medical Physiology, Faculty of Medicine, Menoufia University, Menoufia, Egypt
}

\begin{abstract}
Background: Physical exercise is suggested as a life style modification to improve the age related patho-physiologic heamodynamic alterations.

Aim of Study: The present study was designed to evaluate the possible ameliorating role of aerobic exercise training in improving age associated vascular dysfunction and hemodynamic disturbance.
\end{abstract}

Material and Methods: Thirty male albino rats of local strain were used for this study. Rats were divided into three main groups: The young control (aged 3-4 months, weighing $150-200 \mathrm{gm})(\mathrm{n}=10)$, aged sedentary (aged 22-24 months, weighing 300-400gm) $(\mathrm{n}=10)$ and aged exercised group (aged 22-24 months, weighing 300-400gm) $(n=10)$. Rats in the aged exercised group practiced moderate intensity treadmill exercise for 5 days/week for 6 weeks. After 6 weeks rats were subjected for rat tail-measurement of SBP. Then, fasting retro-orbital blood samples were collected for measuring serum lipid profile (TC, HDL-C, LDL-C, VLDL-C and TGs) and inflammatory cytokine (TNF-a). Lastly, rats were sacrificed and abdominal aorta was exposed for assessing MNV and RP using Doppler ultrasound.

Results: In aged sedentary group, there were significant increase in SBP, RP, serum (TC, LDL-C, HDL-C) and serum TNF-a associated with significant decrement in MNV when compared to the corresponding values in the young control ones. Exercise training for six weeks significantly restored age-related vascular and biochemical changes except for HDL$\mathrm{C}$ and TC there was insignificant diffrence when compared to the corresponding values in aged sedentary group.

Conclusion: Regular exercise training in aging has a beneficial effect on the cardiovascular functions by accelerating blood flow and decreasing resistance to blood flow, also it has an additive beneficial effect on the associated dyslipidemia and chronic inflammatory state in aging.

Key Words: Exercise-Aging-Doppler U/S-Rats.

Correspondence to: Dr. Mohamed H. Hassan, The Department of Medical Physiology, Faculty of Medicine, Menoufia University, Menoufia, Egypt

\section{Introduction}

BIOLOGICAL aging is associated with reduction in the reparative and regenerative potential in tissues and organs. This reduction manifests as a decreased of physiological reserve in response to stress and a time-dependent failure of complex molecular mechanisms that cumulatively create disorder [1].

The most important determinant of cardiovascular health is a person's age. By 2030, approximately $20 \%$ of the population will be aged 65 or older. In this age group, Cardiovascular Diseases (CVD) will result in $40 \%$ of all deaths and rank as the leading cause. Furthermore, the cost to treat cardiovascular disease will triple in that time. Hence, it remains vital that we understand why age is such a critical component of CVD etiology [2].

Aging is associated with increased levels of circulating cytokines and pro inflammatory markers. Aged-related changes in the immune system, known as immune senescence, and increased secretion of cytokines by adipose tissue, represent the major causes of chronic inflammation. This phenomenon is known as "inflamm-aging". High levels of tumor necrosis factor-a, and C-reactive protein are associated in the older subject with increased risk of morbidity and mortality [3]

Clinical studies show a significant relationship between ageing and increased blood pressure, with advancing age being a major non-modifiable risk factor in the development of hypertension [4] Ageing is associated with functional, structural and mechanical changes. These changes that occur in the vasculature, including endothelial dysfunction, vascular remodeling, increased vascular stiff- 
ness, inflammation, atherosclerosis, calcification and increased stiffness [5].

Aging is associated with multiple systemic dysfunctions of the body accompanied by lipid metabolism disorder and chronic inflammatory state which contribute to atherosclerotic CVD [6] Dyslipidemia is characterized by increased Triglyceride (TG) and/or Low-Density Lipoprotein (LDL) levels, and also declined High-Density Lipoprotein (HDL) levels. Such an atherogenic lipid profile often predisposes risk to cardio vascular diseases [7].

Habitual physical activity is proving to strongly benefit health and longevity in humans, including a reduced risk CVDs. Aerobic exercise training has been reported to ameliorate age-associated reductions in both central and peripheral cardiovascular function. For example, cardiac output, stroke volume, and maximal aerobic capacity are increased as a result of exercise training [8].

Furthermore, exercise confers anti-inflammatory actions; exercise suppresses TNF-alpha, and thereby may offer protection against TNF-alpha induced vascular impairment. Regular exercise also promotes mitochondrial health, induces mitochondrial biogenesis, activates mitochondrial antioxidant systems, decreases fat content and attenuates of hyperlipidemia [9]

Previous studies have uncovered an important cross talk between inflammatory processes and generation of ROS in the pathogenesis of cardiovascular aging [10]. Therefore, the present study was conducted to investigate the therapeutic effects and underlying mechanisms of aerobic exercise training on age-related biochemical and vascular haemodynamic changes in aged male rats.

\section{Material and Methods}

The study protocol was approved by the Ethical Committee of Faculty of Medicine, Menoufia University, and was carried out in strict accordance with the recommendations in the guide for the care and use of laboratory animals of the Egyptian Universities. This study followed a randomized controlled animal experimental design, and was carried out at Medical Physiology Department, Faculty of Medicine, Menoufia University, Egypt from 8th of November 2017 till ${ }^{1 \mathrm{st}}$ of March 2018.

\section{Animals:}

Thirty male wistar albino rats of local strain were used in this study. Rats were housed in spacious wire mesh, fully ventilated cages ( 80 X 40
$X 30 \mathrm{~cm})$ in a temperature-controlled room $(25 \pm 1 \mathrm{C})$ and maintained on a 12:12 hour light: Dark cycle with free access to water and food throughout the study period. Strewment was changed every 4 days, and the same person handled the rats throughout the study. Male rats were used to avoid variability caused by hormonal cycles in females as well as because of their more similar homeostatic adaptation (negative energy balance) to exercise in humans compared with female rats $[11,12]$. Rats were acclimatized for 10 days before the start of the study then randomly divided into the following groups, each of 10 animals.

\section{Young control group:}

Ten adult male albino rats (age 3-4 months old, weighing 150-220gm) were fed a standard laboratory chow diet for 6 weeks. Rats were left on the treadmill without running for the same time period as the exercise group to reduce the handling stress on the day of sacrifice.

\section{Aged sedentary group:}

Ten aged male albino rats (age 22-24 month, weighing 300-400gm) maintained under sedentary conditions (untrained) for 6 weeks [13]. Rats were left on the treadmill without running as young control group for the same time period as the exercised group.

\section{Aged exercised group}

Ten aged male albino rats (age 22-24 month, weighing 300-400gm) were exposed to a moderate running exercise program for 6 weeks [13] as the following:

\section{Exercise training protocol:}

Treadmill training began with familiarization of rats with the apparatus for 4 days by placing them on the motorized-driven treadmill. Training group was given exercise training for 5 days/week for 6 weeks. Rats were exercised on the treadmill at a speed of $10 \mathrm{~m} / \mathrm{min}$. The angle of inclination was $0 \%$ gradient and the running time was $15 \mathrm{~min} /$ day. This condition corresponded to a moderate intensity of about $65 \%$ of maximal oxygen consumption [13]. The animals were not exercised for 24h prior to sacrifice [14].

Systolic blood pressure measurement and blood sampling for biochemical assays:

At the end of the experimental period (after 6 weeks), rats were subjected for measurement of systolic BP (SBPmmHg) by Pneumatic pulse transducer (Harvard apparatus Ltd, Aden Berge, England) [15]. Then, animals were fasted overnight and biochemical measurements were performed using 
blood sample collected from the retro-orbital venous plexus of each rat. Blood samples were allowed to clot, then centrifuged for $10 \mathrm{~min}$ at 4000 $\mathrm{rpm}$ and serum was separated and frozen at $-20^{\circ} \mathrm{C}$ till used for measurement of the lipid profile (Total Cholesterol (TC), Low Density Lipoprotein (LDLC), High Density Lipoproteins (HDL-C) and Triglycerides (TGs) were measured using a colorimetric enzymatic method (Bioclin Diagnostic company, Egypt) and Very Low Density Lipoprotein (VLDLC) was calculated according to the formula of TG/5) [14] and tumor necrosis factor-alpha (TNF$\alpha$ ) using an enzyme-linked immunosorbent assay (Quantikine ELISA) method (Abcam Company, Cambridge, UK). All of the above assays were carried out according to the manufacturer's instructions.

Detection of abdominal aorta blood flow using doppler ultrasound:

Blood flow velocity was measured in the rat abdominal aorta by using Bi-directional blood flow meter with FFT-Analysis (HADECO, Japan). The technique for use the probe and application of the flow meter was according to the method described by Ruan et al., [16]. The end diastolic blood flow velocity and the end systolic blood flow velocity were measured and the Resistance Parameter (RP) was calculated [17].

\section{Statistical analysis:}

The data collected were tabulated and analyzed using statistical package for the social sciences (SPSS, Version 20; SPSS Inc., Chicago, Illinois, USA) software, on an IBM compatible computer. The results were expressed as mean \pm Standard Deviation (SD). The significance of differences between groups was determined by one-way analysis of variance (ANOVA) and post-hoc Turkey test was done. $p$-values $\leq 0.05$ were considered statistically significant.

\section{Results}

The presented (Table 1) demonstrate the means \pm SD of (SBP), (MNV), (RP) and serum TNF- $\alpha$ values of the different experimental groups.

The mean value of SBP in the aged sedentary group was significantly higher $(p<0.001)$ when compared to the corresponding value in the control group $(163.10 \pm 20.23$ vs $104.0 \pm 8.48 \mathrm{mmHg})$ respectively. While the mean value of SBP in the aged exercised group $(109.90 \pm 6.80 \mathrm{mmHg})$ was significantly lower $(p<0.001)$ when compared to the corresponding value in the aged sedentary group but it was still significantly higher $(p<0.05)$ when compared to the corresponding value in the young control group (Fig. 1).

Table (1): Systolic Blood Pressure (SBP), Doppler ultrasound parameters (mean value of blood velocity (MNV) and Resistance Parameter (RP), and tumor necrosis factor- $\alpha(\mathrm{TNF}-\alpha)$ values in the young control, aged sedentary and aged exercised groups.

\begin{tabular}{|c|c|c|c|c|}
\hline \multirow{2}{*}{$\begin{array}{l}\text { Para- } \\
\text { meters }\end{array}$} & \multicolumn{3}{|c|}{ Groups } & \multirow{2}{*}{$\begin{array}{c}p- \\
\text { value }\end{array}$} \\
\hline & $\begin{array}{l}\text { Young } \\
\text { control }\end{array}$ & $\begin{array}{c}\text { Aged } \\
\text { sedentary }\end{array}$ & $\begin{array}{c}\text { Aged } \\
\text { exercised }\end{array}$ & \\
\hline - SBP & $104.0 \pm 8.48$ & $163.10 \pm 20.23 *$ & $109.90 \pm 6.80 * \bullet$ & $<0.001 *$ \\
\hline 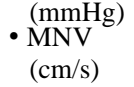 & $2.28 \pm 0.85$ & $0.65 \pm 0.16$ & $1.53 \pm 0.61 *_{\bullet}$ & $<0.001 *$ \\
\hline$\cdot \mathrm{RP}$ & $0.65 \pm 0.10$ & $1.47 \pm 0.22$ & $0.82 \pm 0.13 *_{\bullet}$ & $<0.001 *$ \\
\hline $\begin{array}{r}\text { - TNF- } \alpha \\
(\mathrm{pg} / \mathrm{ml})\end{array}$ & $10.87 \pm 0.72$ & $13.60 \pm 0.50 *$ & $6.37 \pm 0.46^{* \bullet}$ & $<0.001 *$ \\
\hline
\end{tabular}

Results are expressed as mean \pm SD $(n=10)$. Significance was considered when $p$-values $<0.05$.

The marks $*$ and $\bullet$ indicate that values are significantly different when compared to the corresponding values in the control and the aged sedentary groups respectively.

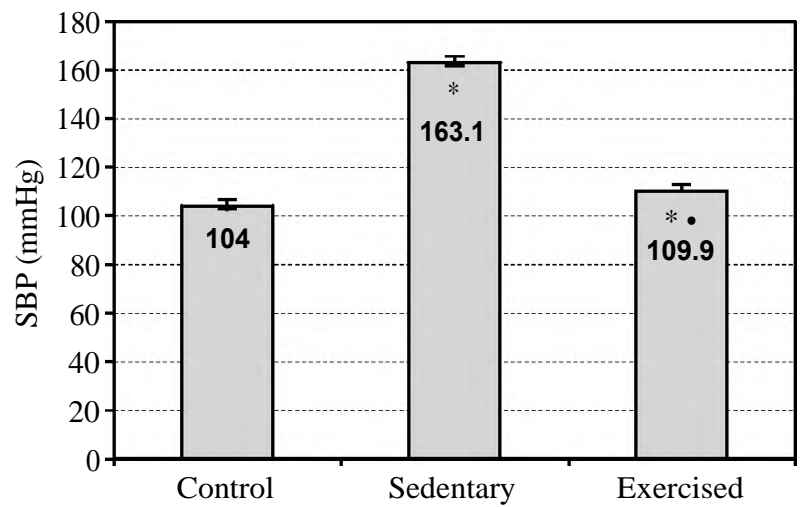

Fig. (1): Systolic blood pressure (SBP $\mathrm{mmHg}$ ) in the young control, aged sedentary and aged exercised groups. Number of rats in each group were ten $(n=10)$. Significance was considered when $p$-value was $\leq 0.05$.

The marks * and $\bullet$ indicate that values are significantly different when compared to the corresponding values in the young control and the aged sedentary groups respectively.

Regarding the doppler findings; (MNV) in the aged sedentary group was significantly lower $(p<0.001)$ when compared to the corresponding value in the young control group ( $0.65 \pm 0.16$ vs $2.28 \pm 0.85 \mathrm{~cm} / \mathrm{s}$ ) respectively. While the mean value of MNV in the aged exercised group $(1.53 \pm 0.61$ $\mathrm{cm} / \mathrm{s})$ was significantly higher $(p<0.05)$ when compared to the corresponding value in the aged sedentary group but, it was still significantly lower $(p<0.05)$ when compared to the corresponding value in the young control group [Fig. (2), panel A]. The mean value of RP in the aged sedentary group was significantly higher $(p<0.001)$ when compared to the corresponding value in the control 
group $(1.47 \pm 0.22$ vs. $0.65 \pm 0.10)$ respectively. While the mean value of RP in the aged exercised group $(0.82 \pm 0.13)$ was significantly lower $(p<0.05)$ when compared to the corresponding value in the aged

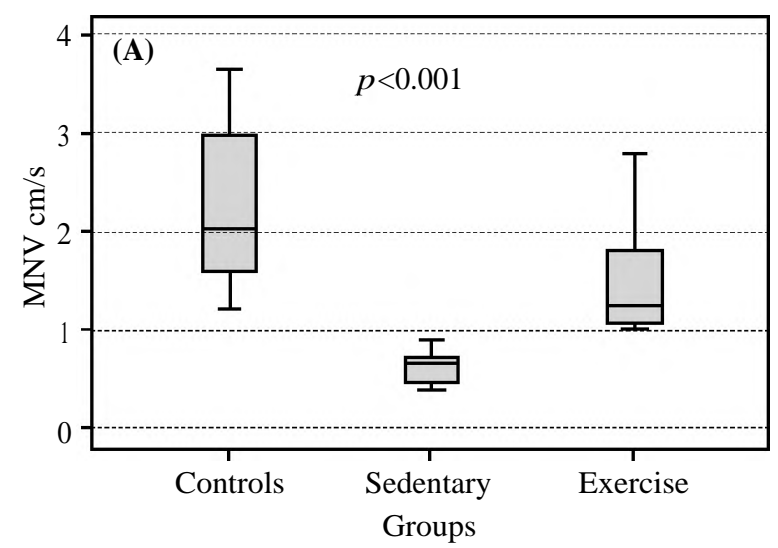

sedentary group, however, it was still significantly higher $(p>0.05)$ when compared to the corresponding value in the young control group [Fig. (2), panel B].

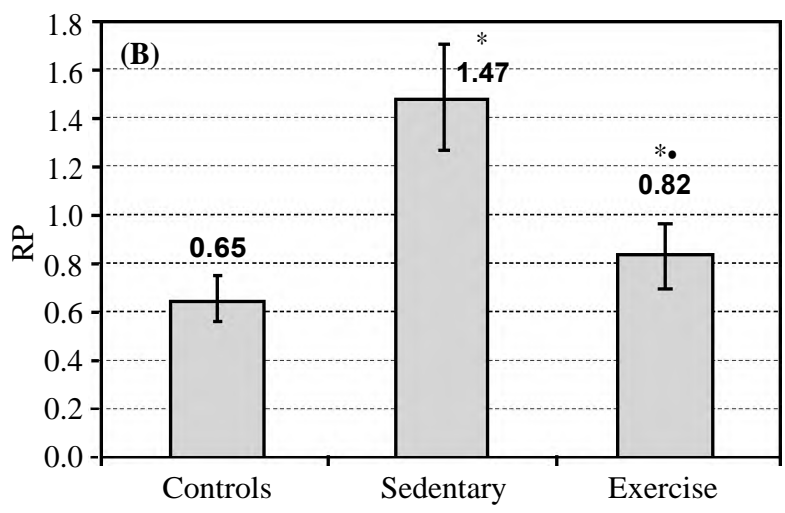

Fig. (2): Mean blood velocity of abdominal aorta (panel A) and Resistance Parameter (panel B) assessed by Doppler flow meter in the young control, aged sedentary and aged exercised groups. Number of rats in each group were ten $(n=10)$. Significance was considered when $p$-value was $\leq 0.05$.

The marks * and $\bullet$ indicate that values are significantly different when compared to the corresponding values in the young control and the aged sedentary groups respectively. Box blot was done to MNV parameter as their values were non-parametric (not normally distributed).

The mean value of TNF- $\alpha$ in the aged sedentary group was significantly higher $(p<0.001)$ when compared to the corresponding value in the young control group $(13.60 \pm 0.50$ vs. $10.87 \pm 0.72 \mathrm{pg} / \mathrm{ml})$ respectively. On the other hand, the mean value of TNF- $\alpha$ in the aged exercised group $(6.37 \pm 0.46$ $\mathrm{pg} / \mathrm{ml})$ was significantly lower $(p<0.001)$ when compared to the corresponding values in both the young control and the aged sedentary groups Fig. (3).

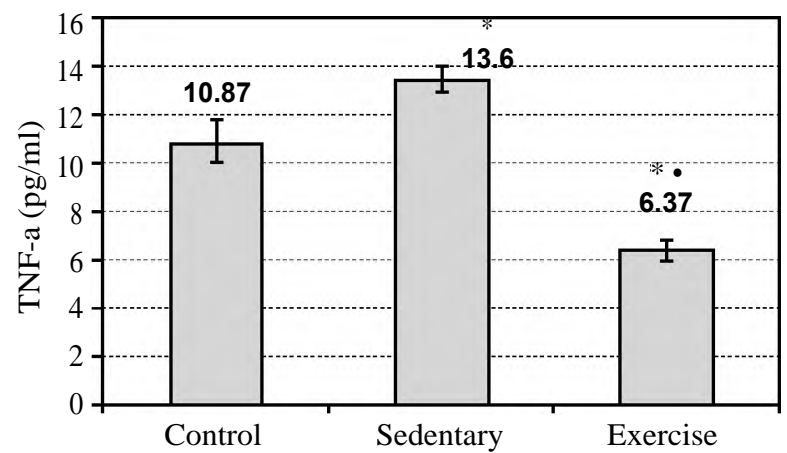

Fig. (3): Serum tumor necrosis factor-alpha in the young control, aged sedentary and aged exercised groups. Number of rats in each group were ten $(n=10)$. Significance was considered when $p$-value was $\leq 0.05$.

The marks * and $\bullet$ indicate that values are significantly different when compared to the corresponding values in the young control and the aged sedentary groups respectively.

The presented (Table 2) demonstrate the means \pm SD of the fasting serum lipid profile (TC, HDL-
C, LDL-C, VLDL-C and TGs) in the young control, aged sedentary and aged exercised groups.

Table (2): Fasting serum lipid profile [Total Cholesterol (TC), High Density Lipoprotein Cholesterol (HDL-C), Low Density Lipoprotein Cholesterol (LDL-C), Very Low Density Lipoprotein Cholesterol (VLDLC) and Triglycerides (TG)] in the young control, aged sedentary and aged exercised groups.

\begin{tabular}{|c|c|c|c|c|}
\hline \multirow{2}{*}{ Parameters } & \multicolumn{3}{|c|}{ Groups } & \multirow{2}{*}{$\begin{array}{c}p- \\
\text { value }\end{array}$} \\
\hline & $\begin{array}{l}\text { Young } \\
\text { control }\end{array}$ & $\begin{array}{c}\text { Aged } \\
\text { sedentary }\end{array}$ & $\begin{array}{c}\text { Aged } \\
\text { exercised }\end{array}$ & \\
\hline - $\mathrm{TC}$ (mg/dl) & $53.98 \pm 16.96$ & $73.10 \pm 18.30^{*}$ & $62.44 \pm 16.78$ & $0.055 *$ \\
\hline $\begin{array}{r}\cdot \text { HDL-C } \\
(\mathrm{mg} / \mathrm{dl})\end{array}$ & $13.21 \pm 4.23$ & $21.20 \pm 8.44^{*}$ & $23.40 \pm 12.60$ & 0.072 \\
\hline $\begin{array}{r}\cdot \text { LDL-C } \\
(\mathrm{mg} / \mathrm{dl})\end{array}$ & $32.59 \pm 14.43$ & $45.11 \pm 12.21^{*}$ & $31.64 \pm 6.53 \bullet$ & $0.020 *$ \\
\hline $\begin{array}{l}\text { - VLDL-C } \\
(\mathrm{mg} / \mathrm{dl})\end{array}$ & $8.17 \pm 1.26$ & $7.38 \pm 2.02$ & $7.39 \pm 2.06$ & 0.547 \\
\hline - TGs (mg/dl) & $40.88 \pm 6.31$ & $36.95 \pm 10.13$ & $37.05 \pm 10.34$ & 0.555 \\
\hline
\end{tabular}

Results are expressed as mean \pm SD $(n=10)$. Significance was considered when $p$-values $<0.05$.

The marks $*$ and $\bullet$ indicate that values are significantly different when compared to the corresponding values in the young control and the aged sedentary groups respectively.

The mean value of TC in the aged sedentary group was significantly higher $(p<0.05)$ when compared to the corresponding value in the control group $(73.10 \pm 18.30$ vs. $53.98 \pm 16.96 \mathrm{mg} / \mathrm{dl})$ respectively. While the mean value of TC in the aged exercised group $(62.44 \pm 16.78 \mathrm{mg} / \mathrm{dl})$ was insignificantly different $(p>0.05)$ when compared to the corresponding values in both young control and the aged sedentary groups [Fig. (4), panel A]. 
The mean value of HDL-C in the aged sedentary group was significantly higher $(p<0.05)$ when compared to the corresponding value in the young control group $(21.20 \pm 8.44$ vs. $13.21 \pm 4.23 \mathrm{mg} / \mathrm{dl})$ respectively. While the mean value of HDL-C in the aged exercised group $(23.40 \pm 12.6023 \mathrm{mg} / \mathrm{dl})$ was insignificantly different $(p>0.05)$ when compared to the corresponding values in both the young control and the aged sedentary groups [Fig. (4), panel B].

The mean value of LDL-C in the aged sedentary group was significantly higher $(p<0.05)$ when compared to the corresponding value in the young control group $(45.11 \pm 12.21$ vs. $32.59 \pm 14.43 \mathrm{mg} / \mathrm{dl})$ respectively. While the mean value of LDL-C in the aged exercised group $(31.64 \pm 6.53 \mathrm{mg} / \mathrm{dl})$ was
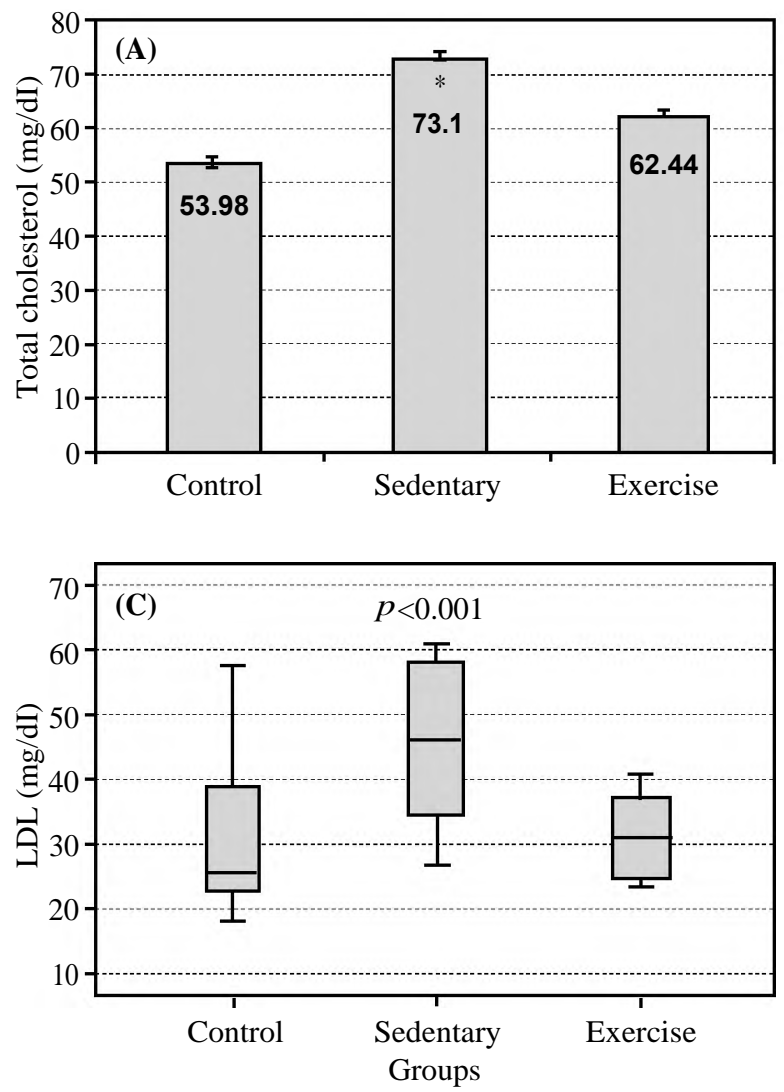

Discussion

Ageing is associated with functional, structural and mechanical changes in arteries that closely resemble the vascular alterations in hypertension which include endothelial dysfunction, vascular remodeling, inflammation, calcification and increased stiffness. The mechanisms underlying vascular alterations in ageing and hypertension are common and include dyslipidemia, oxidative stress and activation of pro inflammatory and pro-fibrotic transcription factors [18]. Exercise training has significantly lower $(p<0.05)$ when compared to the corresponding value in the aged sedentary group but, there was insignificant difference ( $p>$ 0.05 ) in the mean value of LDL-C between the aged exercised and the young control groups [Fig. (4), panel C].

There was insignificant difference $(p>0.05)$ in the mean values of VLDL-C between the young control, the aged sedentary and the aged exercised groups $(8.17 \pm 1.26,7.38 \pm 2.02$ and $7.39 \pm 2.06 \mathrm{mg} / \mathrm{dl})$ respectively. Also, there was insignificant difference $(p>0.05)$ in the mean value of TGs between the young control, aged sedentary and aged exercised groups $(40.88 \pm 6.31,36.95 \pm 10.13$ and $37.05 \pm 10.34$ $\mathrm{mg} / \mathrm{dl}$ ) respectively.

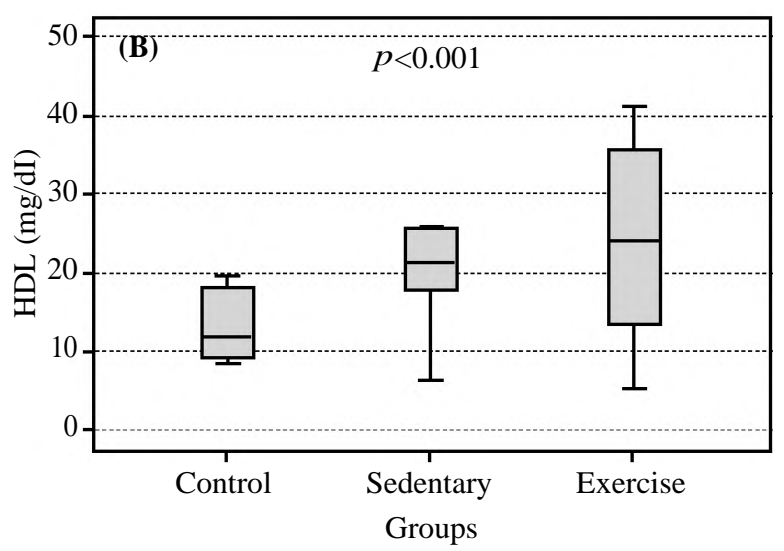

Fig. (4): Fasting serum total cholesterol (panel A), Fasting serum high density lipoprotein-cholesterol (panel B) and fasting serum low density lipoprotein-cholesterol (panel C) in the control, aged sedentary and aged exercised groups. Number of rats in each group were ten $(n=10)$. Significance was considered when $p$-value was $\leq 0.05$.

The mark * indicate this value is significantly different when compared to the corresponding value in the young control group. Box blot was done to HDL-C and LDL-C parameters as their data was non-parametric (not normally distributed).

been reported to ameliorate age-associated reductions in both central and peripheral cardiovascular function. Also, it reverses old age-associated reductions in endothelium dependent vasodilatation in humans [19]. Therefore, physical activity has been recommended as a non-pharmacological approach for the treatment and control of age-induced vascular disorders [20].

The present study was conducted to evaluate the impact of regular exercise for 6 weeks on systolic blood pressure, blood velocity, vascular 
resistance and lipid profile in aged rats. Also, we investigated the impact of exercise on pro-inflammatory cytokines in these aged rats.

In the current study, the mean value of SBP was significantly higher in the aged sedentary rats when compared to the corresponding value in the young control ones. This result was in agreement with the previous reported researches $[4,18]$. Hypertension with advancing age may be caused by the changes that occur in the vasculature, including endothelial dysfunction, vascular remodelling, increased vascular stiffness and inflammation [5] In addition, aging is further associated with endothelial cell production of vasoconstricting growth factors such as angiotensin II and endothelin, whereas vasodilatatory factors such as nitric oxide, prostacyclin are reduced [21]

The present study clearly demonstrated that, moderate exercise training resulted in significant decrement in the mean value of SBP when compared to the corresponding value in the aged sedentary animals; however, it was still significantly higher when compared to the young control ones. The attenuating effect of exercise on age-induced hypertension was in agreement with the reports of many researchers that stated that, regular aerobic exercise decreased systolic blood pressure by 3.84 $\mathrm{mmHg}$ and diastolic blood pressure by $2.58 \mathrm{mmHg}$ [22]. The ameliorating effect of regular exercise training on SBP may be due to enhancement of the expression of genes associated with local vasodilatory signaling [23]. Also regular aerobic exercise protects against age-dependent elastic arterial stiffness and vascular endothelial dysfunction by modulating structural proteins, reducing oxidative stress, decreasing inflammatory mediators, and restoring nitric oxide bioavailability [24]

In the present study, our results demonstrated that, the mean value of MNV was significantly lower while the mean value of RP was significantly higher in the aged sedentary rats when compared to the corresponding values in the young control ones. These results were in agreement with previous studies by $[25,26]$. On the other hand, in the aged exercised group, the mean value of MNV was significantly higher and RP was significantly lower when compared to the corresponding values in the aged sedentary rats. These results were in agreement with previous studies by $[27,28]$.

The effect of aging on MNV and RP may be explained by that; the aged vessels are exposed to less hemodynamic stress due to reduced blood flow caused by decline in heart function; in addi- tion, endothelial cells become less responsive to shear stress, resulting in a decline in the protective vasodilator NO [26]. Also, the aging of the vasculature leads to increase arterial thickening and stiffness as well as dysfunctional endothelium. Clinically, these changes result in increased systolic pressure and present major risk factors for development of atherosclerosis and hypertension [29] This vascular dysfunction leads to loss of adequate tissue perfusion (resulting in diminished blood flow), insufficient vascular growth or regression (resulting in hypertension) [25]

The ameliorative effect of exercise on MNV and RP was reported by Prior and Green et al., who found that there was a relationship between increased shear stress on the endothelium and increased nitric oxide and prostacyclin release which leads to increase in the caliber of the large conduit vessels consequently increased blood flow through the vessel lumen in exercise training since vessel resistance is a function of the radius [27,30]. Also, the reduction in muscle tissue oxygen tension in the exercising muscle is associated with reduction in vascular resistance [31]. Furthermore, metabolically linked vasodilatation in exercising skeletal muscle is associated with reduced response to adrenergically mediated vasoconstrictor mechanisms [32]. The fact that vascular resistance falls in spite of increased vasomotor tone caused by sympathetic stimulation is further evidence of the sympatholytic nature of the vasodilatation in exercising skeletal muscle [33]. Also, regular exercise training resulted in decreased blood viscosity and consequently reduction in the systemic peripheral resistance [34]

Dyslipidemia is a well-established risk factor for cardiovascular disease in elderly and is estimated to account for more than half of the global cases of coronary artery disease [35]. Physical exercise is an important strategy to avert many of the observed age-related physiological decrements on the traditional risk factors as (blood lipids, hypertension, diabetes etc.) [36,37].

In our hands, the mean value of TC, HDL-C and LDL-C were significantly higher in the aged sedentary rats when compared to the corresponding values in young control ones. These results were in agreement with previous studies by [38-41]. While in the aged exercise group, the mean value of LDL$\mathrm{C}$ was significantly lower, but there was insignificant difference in the mean values of HDL-C \& TC when compared to the corresponding values in the aged sedentary rats, these results were consistent with the published studies [42-44]. Also, there were insignificant change in the mean values 
of VLDL-C and TGs among the experimental groups.

The increased level of TC in the aged sedentary group may be caused by the age-related gradual reduction in the capacity for plasma cholesterol clearance through Reverse Cholesterol Transport (RCT), which is a biologic process transferring cholesterol to bile acid through the liver [45], also, a decline in the activity of the bile acid biosynthesis by cholesterol 7 hydroxylase, confirmed in the aging rat [46]. An interesting theory suggests that the relative deficiency in Growth Hormone (GH), occurring with normal aging in both humans and rats [47] brings about the development of the agerelated hypercholesterolemia, as GH exerts several important effects on lipid metabolism in adult humans and animals [38]. GH secretion declines by $14 \%$ on the average with each decade in normal adults after 20 years old [48].

Regarding the increased serum level of HDL$\mathrm{C}$ in aged sedentary group, astudy by Le Couteur et al., reported that, elevated HDL-C level in elderly men may be due to age-related changes in the ultrastructure of the liver sinusoidal endothelial cells which associated with an increased expression of von Willebrand's factor (vWF, a capillary marker) in all species and laminin and collagen in rats leading to dyslipidemia in old age, including lipoprotein disposition, reduction in endocytosis and decrease of hepatic blood flow in addition to the structural changes of pseudocapillarization might impair the hepatic uptake of lipoproteins including HDL-C thus contributing to age-related increase in HDL-C in the elderly [49]. In contrary to our result, walter et al reported that, the decrement of HDL plasma concentrations with age may be due to hormonal changes, inflammatory processes, and diabetes mellitus [39] as insulin resistance and impaired lipolysis are more frequent at advanced age and may impair RCT which is the major determinant of HDL [50]. Inflammatory processes in aged people may cause low HDL cholesterol by physical replacement of apolipoprotein A-I with the acute-phase reactant Serum Amyloid A (SAA) and various cytokine-induced changes [51]. HDL metabolism is influenced by hormones that change with age. In aging men, a low testosterone level show a positive correlation with HDL concentration. As testosterone decline itself may impair lipoprotein lipase activity and RCT that impair HDL formation [52]

Concerning the increased level of LDL-C in the aged sedentary rats Liu and $\mathrm{Li}$ reported that aging is associated with increase in the release of
FFAs from adipocytes and a decrease in the mass of metabolically active tissue combined with a decrease in the oxidative capacity of tissues, the net effect of these cellular changes is increased blood levels of FFA which results in hyperinsulinemia with insulin resistance and an inflow of fatty acids from the adipose tissue to the liver, leading to gluconeogenesis and an increase in the production of LDL [41]

On the other side, the lowering effect of regular exercise training on LDL-C could be explained by the preference of muscle tissue for fatty acids and carbohydrates for the production of muscle energy which increase adipose tissue lipolysis [53] and cause a significant decrease in LDL-C [54]

A traditional understanding of "inflamm-aging" suggests that low-grade inflammation increases during aging and can be measured by levels of proinflammatory markers [55]. Our results showed that the mean value of serum TNF-alpha was significantly higher in aged sedentary group when compared to the corresponding value in the young control group. This result was in agreement with previous study [56], however, in aged exercised group the mean value of TNF- a was significantly lower when compared to the corresponding values in both the aged sedentary and young control groups, this result was consistent with other reported results [56,57]

The increased inflammatory markers in aged sedentary rats in the present investigation can be attributed to the increase in the total and visceral adiposity with age also declining levels of sex hormones have been proposed for mechanisms to increase pro inflammatory cytokines [55]. Adipose tissue acts as an active endocrine organ, capable of secreting several cytokines and adipokines, including IL-6 and TNF-alpha [58] . Increased oxidative stress with aging may also contribute to the development of chronic inflammation and disease. It was well established that aging is associated with high level of Reactive Oxygen Species (ROS), as well as low level in antioxidant capacity [59] ROS activation of toll-like receptors on a variety of immune cells play an important role in activating the inflammatory cascade [60]

Our results in the aged exercised group obviously indicate that, exercise training effectively counteracts some of the disrupting inflammatory effects seen in the aged sedentary rats. This effect of exercise may be ascribed to that, regular exercise reduces fat mass and adipose tissue which is known to contribute to systemic inflammation because, 
TNF-alpha is produced in adipose tissue [61] and A recent clinical trial demonstrated that anti TNF-alpha treatment enhanced high-density lipoprotein without influencing low-density lipoprotein, indicating that TNF-alpha causes a risk lipid profile [63].Another possibility is that, regular exercise reduces oxidative stress by up-regulating endogenous anti-oxidant defense systems [64]. Moreover, a study by Harbuz, et al., reported that exercise training activates the hypothalamic-pituitaryadrenal axis and sympathetic nervous systems. Cortisol is known to have potent anti-inflammatory effects, and catecholamines can inhibit pro-inflammatory cytokine production [65]. Exercise training might reduce systemic inflammation in the elderly because it increases muscle production of IL- 6 [66]. Starkie et al., reported that exercise and IL6 infusion could inhibit endotoxin-induced production of TNF-a in humans circumstantially suggesting that IL-6 can act in an anti-inflammatory fashion

\section{Conclusion:}

Regular exercise offers protection against aged induced vascular dysfunction primarily by improving dyslipidemia and indirectly offers protection against the disturbance in laminar blood flow by augmenting the blood velocity and decreasing the vascular resistance. Also it decreases the inflammatory status in aging by inhibiting the production of the pro-inflammatory cytokine (TNF-alpha) and hence suppresses the systemic low-grade inflammation.

\section{References}

1- KHAN S.S., B.D. SINGER and D.E. VAUGHAN: Molecular and physiological manifestations and measurement of aging in humans. Aging cell., 16 (4): p. 624-33, 2017.

2- FLEG J.L., W.S. ARONOW and W.H. FRISHMAN: Cardiovascular drug therapy in the elderly: Benefits and challenges. Nature Reviews Cardiology, 8 (1): p. 13, 2011.

3- MICHAUD M., et al.: Proinflammatory cytokines, aging, and age-related diseases. Journal of the American Medical Directors Association, 14 (12): p. 877-82, 2013.

4- WANG M., R.E. MONTICONE and E.G. LAKATTA: Arterial aging: A journey into subclinical arterial disease. Current Opinion In Nephrology and Hypertension, 19 (2): p. 201, 2010.

5- BARJA G.: Updating the mitochondrial free radical theory of aging: An integrated view, key aspects, and confounding concepts. Antioxidants \& redox signaling, 19 (12): p. 1420-45, 2013.

6- POHLEL K., et al.: Treating dyslipidemia in the elderly. Current Opinion in Lipidology, 17 (1): p. 54-7, 2006.

7- PERDOMO G. and H.H. DONG: Apolipoprotein D in lipid metabolism and its functional implication in athero- sclerosis and aging. Aging (Albany NY), 1 (1): p. 17 2009.

8- CHODZKO-ZAJKO W.J., et al.: Exercise and physical activity for older adults. Medicine \& Science in Sports \& Exercise, 41 (7): p. 1510-30, 2009.

9- UNGVARI Z., et al.: Mechanisms of vascular aging: New perspectives. Journals of Gerontology Series A: Biomedical Sciences and Medical Sciences, 65 (10): p. 1028-41, 2010.

10- EL-ASSAR M., J. ANGULO and L. RODRÍGUEZMAÑAS: Oxidative stress and vascular inflammation in aging. Free Radical Biology and Medicine, 65: p. 380$401,2013$.

11- PI-SUNYER F.X. and R. WOO: Effect of exercise on food intake in human subjects. The American Journal of Clinical Nutrition, 42 (5): p. 983-90, 1985.

12- TITCHENAL C.A.: Exercise and food intake. Sports Medicine, 6 (3): p. 135-45, 1988.

13- THIRUNAVUKKARASU V., et al.: Influence of 6-week exercise training on erythrocyte and liver antioxidant defense in hyperinsulinemic rats. Comparative Biochemistry and Physiology Part C: Toxicology \& Pharmacology, 135 (1): p. 31-7, 2003.

14- GHANBARI-NIAKI A., et al.: Treadmill exercise enhances ABCA1 expression in rat liver. Biochemical and Biophysical Research Communications, 361 (4): p. 841-6, 2007.

15- FUJITA K., et al.: Role of endothelin-1 and the ETA receptor in the maintenance of deoxycorticosterone acetatesalt-induced hypertension. British Journal of Pharmacology, 114 (5): p. 925-30, 1995.

16- RUAN X., et al.: Renal Vascular Reactivity in Mice AngIIInduced Vasoconstriction in AT 1A Receptor Null Mice. Journal of the American Society of Nephrology, 10 (12): p. 2620-30, 1999.

17- DAI W., et al.: Ultrasonic characteristics and clinical significance of umbilical cord blood flow in acute fetal distress. Journal of Acute Disease, 5 (6): p. 483-7, 2016.

18- HARVEY A., A.C. MONTEZANO and R.M. TOUYZ Vascular biology of ageing-Implications in hypertension. Journal of Molecular and Cellular Cardiology, 83: p. 11221, 2015.

19- SINDLER A.L., et al.: Nitrite supplementation reverses vascular endothelial dysfunction and large elastic artery stiffness with aging. Aging cell, 10 (3): p. 429-37, 2011.

20- AHMED N., et al.: Compliance to antihypertensive drugs, salt restriction, exercise and control of systemic hypertension in hypertensive patients at Abbottabad. J. Ayub. Med. Coll. Abbottabad., 20 (2): p. 66-9, 2008.

21- WANG M., et al.: Proinflammatory profile within the grossly normal aged human aortic wall. Hypertension, 50 (1): p. 219-27, 2007.

22- WHELTON S.P., et al.: Effect of aerobic exercise on blood pressure: A meta-analysis of randomized, controlled trials. Annals of Internal Medicine, 136 (7): p. 493-503, 2002.

23- MAEDA S., et al.: Aortic stiffness and aerobic exercise: Mechanistic insight from microarray analyses. Medicine and Science in Sports and Exercise, 37 (10): p. 1710-6, 2005. 
24- Eckel R.H., et al.: 2013 AHA/ACC guideline on lifestyle management to reduce cardiovascular risk: A report of the American College of Cardiology/American Heart Association Task Force on Practice Guidelines. Journal of the American College of Cardiology, 63 (25 Part B): p. 2960-84, 2014

25- IZZO Jr., J.L. and B.E. SHYKOFF: Arterial stiffness: Clinical relevance, measurement, and treatment. Rev. Cardiovasc. Med., 2 (1): p. 29-40, 2001.

26- KANG L.S., R.A. REYES and J.M. MULLER-DELP: Aging impairs flow-induced dilation in coronary arterioles: Role of NO and H2O2. American Journal of PhysiologyHeart and Circulatory Physiology, 297(3): p. H1087H1095, 2009.

27- GREEN D.J., et al.: Effect of exercise training on endothelium-derived nitric oxide function in humans. The Journal of Physiology, 561 (1): p. 1-25, 2004.

28- HOGAN T.S.: Exercise-induced reduction in systemic vascular resistance: A covert killer and an unrecognised resuscitation challenge? Medical Hypotheses, 73 (4): p. 479-84, 2009.

29- LAKATTA E.G.: Arterial and cardiac aging: Major shareholders in cardiovascular disease enterprises: Part III: Cellular and molecular clues to heart and arterial aging. Circulation, 107 (3): p. 490-7, 2003.

30- PRIOR B.M., H. YANG and R.L. TERJUNG: What makes vessels grow with exercise training? Journal of Applied Physiology, 97 (3): p. 1119-28, 2004.

31- CALBET J.A., et al.: Cardiac output and leg and arm blood flow during incremental exercise to exhaustion on the cycle ergometer. Journal of APPLIED PHYsiology, 103 (3): p. 969-78, 2007.

32- WRAY D.W., et al.: Acute sympathetic vasoconstriction at rest and during dynamic exercise in cyclists and sedentary humans. Journal of Applied Physiology, 102 (2): p. 704-12, 2007.

33- OGOH S., et al.: Arterial baroreflex control of muscle sympathetic nerve activity in the transition from rest to steady-state dynamic exercise in humans. American Journal of Physiology-Heart and Circulatory Physiology, 293 (4): p. H2202-H2209, 2007.

34- ROMAIN A.J., et al.: Effects of exercise training on blood rheology: A meta-analysis. Clinical Hemorheology and Microcirculation, 49 (1-4): p. 199-205, 2011.

35- SHANMUGASUNDARAM M., S.J. ROUGH and J.S ALPERT: Dyslipidemia in the elderly: Should it be treated? Clinical Cardiology, 33 (1): p. 4-9, 2010.

36- SINGH M.A.F.: Exercise comes of age: Rationale and recommendations for a geriatric exercise prescription. The Journals of Gerontology Series A: Biological Sciences and Medical Sciences, 57 (5): p. M262-M282, 2002.

37- JOYNER M.J. and D.J. GREEN: Exercise protects the cardiovascular system: Effects beyond traditional risk factors. The Journal of Physiology, 587 (23): p. 5551-8, 2009.

38- PARINI P., B. ANGELIN and M. RUDLING: Cholesterol and lipoprotein metabolism in aging: Reversal of hypercholesterolemia by growth hormone treatment in old rats. Arteriosclerosis, Thrombosis, and Vascular Biology, 19 (4): p. 832-9, 1999.
39- WALTER M.: Interrelationships among HDL metabolism, aging, and atherosclerosis. Arteriosclerosis, Thrombosis, and Vascular Biology, 29 (9): p. 1244-50, 2009.

40- CARROLL M.D., B.K. KIT and D.A. LACHER: Total and high-density lipoprotein cholesterol in adults: National Health and Nutrition Examination Survey. Target, p. 2 (17), 2010.

41- LIU H.H. and J.J. LI: Aging and dyslipidemia: A review of potential mechanisms. Ageing Research Reviews, 19: p. 43-52, 2015.

42- KANG H.S., et al.: Physical training improves insulin resistance syndrome markers in obese adolescents. Medicine and Science in Sports and Exercise, 34 (12): p. 1920-7, 2002

43- YOSHIDA H., et al.: Effects of supervised aerobic exercise training on serum adiponectin and parameters of lipid and glucose metabolism in subjects with moderate dyslipidemia. Journal of atherosclerosis and thrombosis, 17 (11): p. 1160-6, 2010.

44- ALBARRATI A.M., et al.: Ef ectiveness of Low to Moderate Physical Exercise Training on the Level of LowDensity Lipoproteins: A Systematic Review. Bio. Med. Research International, 2018.

45- EINARSSON K., et al.: Influence of age on secretion of cholesterol and synthesis of bile acids by the liver. New England Journal of Medicine, 313 (5): p. 277-82, 1985.

46- STAHLBERG D., B. ANGELIN and K. EINARSSON: Age-related changes in the metabolism of cholesterol in rat liver microsomes. Lipids, 1. 26 (5): p. 349-52, 1991.

47- CORPAS E., S.M. HARMAN and M.R. BLACKMAN: Human growth hormone and human aging. Endocrine reviews, 14 (1): p. 20-39, 1993.

48- BOUILLANNE O., et al.: Growth hormone therapy in elderly people: An age-delaying drug? Fundamental \& Clinical Pharmacology, 1. 10 (5): p. 416-30, 1996.

49- Le COUTEUR D.G., et al.: Hepatic pseudocapillarisation and atherosclerosis in ageing. The Lancet, 359 (9317): p. 1612-5, 2002.

50- ROHRER L., M. HERSBERGER, and A. VON ECKARDSTEIN: High density lipoproteins in the intersection of diabetes mellitus, inflammation and cardiovascular disease. Current opinion in lipidology, 15 (3): p. 269-78, 2004.

51- VAN DER WESTHUYZEN, D.R., F.C. De BEER and N.R. WEBB: HDL cholesterol transport during inflammation. Current Opinion in Lipidology, 18 (2): p. 147 51, 2007.

52- MINAMINO T. and I. KOMURO: Vascular cell senescence: Contribution to atherosclerosis. Circulation research, 100 (1): p. 15-26, 2007.

53- SILVEIRA L.R., et al.: Regulação do metabolismo de glicose e ácido graxo no músculo esquelético durante exercício físico. Arquivos Brasileiros de Endocrinologia \& Metabologia, 55 (5): p. 303-13, 2011.

54- CHEIK N.C., et al.: Efeito de diferentes frequiências de exercício físico na prevenção da dislipidemia e da obesidade em ratos normo e hipercolesterolêmicos. Revista Brasileira de Educação Física e Esporte, 20 (2): p. 1219, 2006. 
55- SINGH T. and A.B. NEWMAN: Inflammatory markers in population studies of aging. Ageing Research Reviews, 10 (3): p. 319-29, 2011.

56- PEDERSEN B.K.: Anti-inflammatory effects of exercise: Role in diabetes and cardiovascular disease. European Journal of Clinical Investigation, 47 (8): p. 600-11, 2017.

57- PETERSEN A.M.W. and B.K. PEDERSEN: The antiinflammatory effect of exercise. Journal of APPLIED Physiology, 98 (4): p. 1154-62, 2005.

58- TRAYHURN P. and I. WOOD: Signalling role of adipose tissue: Adipokines and inflammation in obesity. Portland Press Limited, 2005.

59- KREGEL K.C. and H.J. ZHANG: An integrated view of oxidative stress in aging: Basic mechanisms, functional effects, and pathological considerations. American Journal of Physiology-Regulatory, Integrative and Comparative Physiology, 292 (1): p. R18-R36, 2007.

60- GILL R., A. TSUNG and T. BILLIAR: Linking oxidative stress to inflammation: Toll-like receptors. Free Radical Biology and Medicine, 2. 48 (9): p. 1121-32, 2010.

61- HARKINS J.M., et al.: Expression of interleukin-6 is greater in preadipocytes than in adipocytes of 3T3-L1 cells and C57BL/6J and ob/ob mice. The Journal of Nutrition, 134 (10): p. 2673-77, 2004.

62- COPPACK S.W.: Pro-inflammatory cytokines and adipose tissue. Proceedings of the Nutrition Society, 60 (3): p. 349-56, 2001

63- TOUSSIROT E., et al.: Adiponectin in autoimmune diseases. Current medicinal chemistry, 19 (32): p. 5474 80, 2012.

64- CHUNG H.Y., et al.: Molecular inflammation: Underpinnings of aging and age-related diseases. Ageing Research Reviews, 8 (1): p. 18-30, 2009.

65- HARBUZ M.S., A.J. CHOVER-GONZALEZ, and D.S JESSOP: Hypothalamo-pituitary-adrenal axis and chronic immune activation. Annals of the New York Academy of Sciences, 992 (1): p. 99-106, 2003.

66- FEBBRAIO M.A. and B.K. PEDERSEN: Muscle-derived interleukin-6: Mechanisms for activation and possible biological roles. The FASEB Journal, 16 (11): p. 133547, 2002.

67- STARKIE R., et al.: Exercise and IL-6 infusion inhibit endotoxin-induced TNF-a production in humans. The FASEB Journal, 17 (8): p. 884-6, 2003.

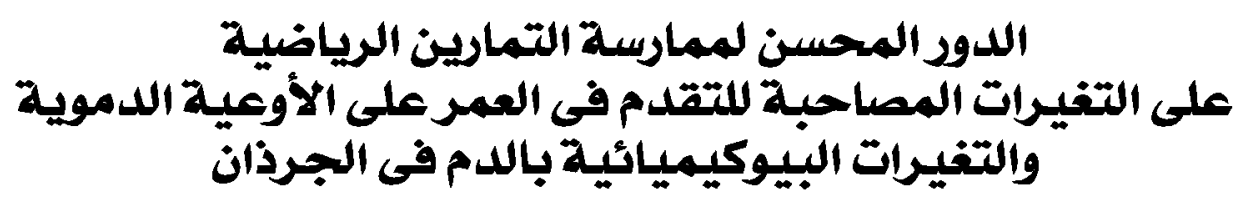

الأهداف: صممت هذه الدراسة الحالية لتقييم دود ممارسة التمارين الرياضية فى تحسين الضعف فى الأوعية الدموية المصاحبة للعمر والاضطرابات في الدورة الدموية.

مقدمة: تمثل التمارين الرياضية نمط حياة مختف لتحسين التغيرات الديناميكية الدموية وكذلك التغيرات المرضية الفسيولوهية المتعلقة بالعمر.

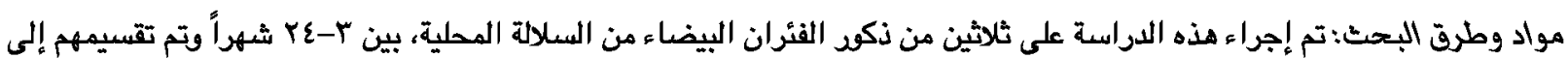

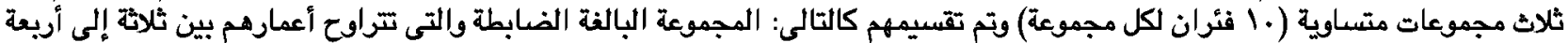

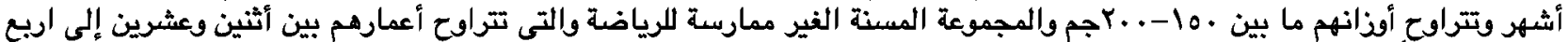

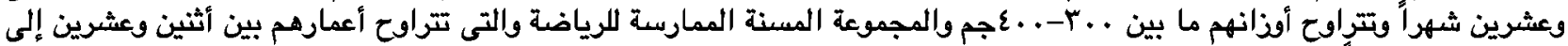

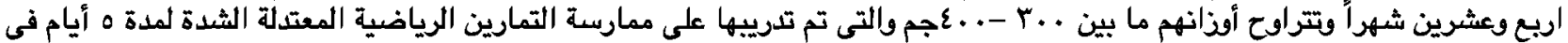

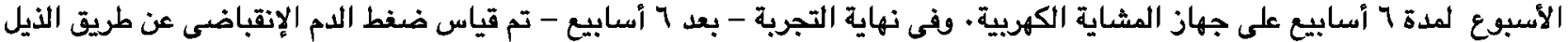

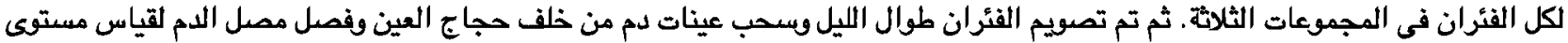

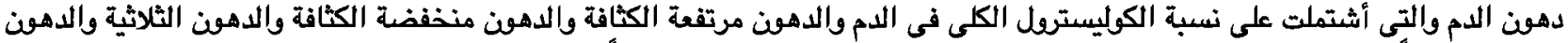

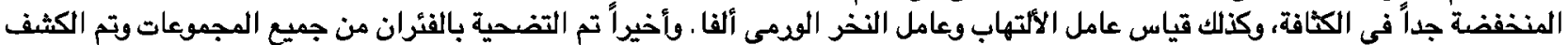

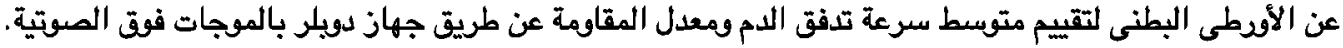

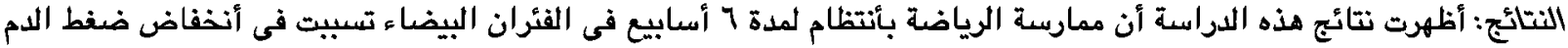

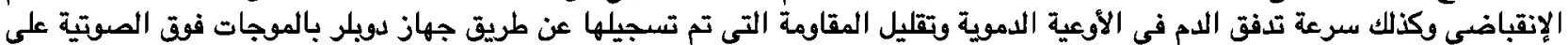

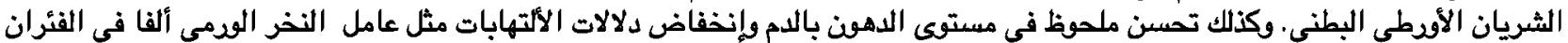
المسنة الممارسة للرياضة مقارنة بالفئران المسنة الغير ممارسة لإنيان الرياضة.

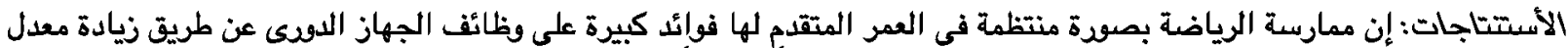

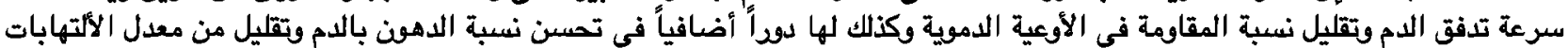
المزمنة المصاحبة للتقدم فى العمر. 